\title{
Panóptico, utopía y alteridad en Museo de la Novela de la Eterna*
}

\section{Panoctic, utopia and otherness in Museo de la Novela de la Eterna}

\section{GiLberto Triviños}

Universidad de Concepción. Concepción, Chile.

gtrivino@udec.cl

"El arte nos va aproximando, a través de experimentos, a la patria que ilumina todos sus paisajes de deseo" Ernst Bloch

\section{RESUMEN}

Una novela argentina del siglo XX tiene gran importancia dentro de lo que podríamos denominar la historia hispánica, aún no escrita, de las insurrecciones del deseo contra el dispositivo panóptico que funda la ilusión del disciplinamiento de sus flujos perturbadores en la alucinación del lector por la verosimilitud o mimesis. En Museo de la Novela de la Eterna. Macedonio Fernández, su autor, cifra en ella la escisión acaso más escandalosa y a la vez más conmovedora entre el deseo y el orden realista, entre la pasión metafísica de la negación de la muerte y la forma narrativa que la somete a rituales de expulsión.

Palabras claves: Museo de la Novela de la Eterna, novela realista/novela metafísica, muerte, esperanza.

*Este artículo forma parte del Proyecto Fondecyt No 1060747 "Panoptismo y antipanoptismo en la novela hispanoamericana". 


\section{ABSTRACT}

One twentieth century Argentinean novel is of great importance within what we might call Hispanic History, not written yet, of the insurrections of desire against the panoptic mechanism that bases the illusion of disciplinary action of its disturbing flows in the reader's hallucination because of the verisimilitude or mimesis. This novel is Museo de la Novela de la Eterna, Macedonio Fernández, its author, presents perhaps the most scandalous and at the same time the most moving scission between desire and the realistic order, between metaphysical passion of the negation of death and the narrative form that submits it to expulsion rituals.

Keywords: Museo de la Novela de la Eterna, realistic novel/metaphysical novel, death, hope.

Recibido: 31-08-2009.

Aceptado: 28-09-2009.

a novela panóptica, en una primera aproximación, es un dispositivo disciplinario, en el ámbito de la ficción narrativa moderna, equivalente a los recintos cerrados descritos por Foucault: manicomio, cuartel, prisión, escuela. Las novelas realistas del siglo XIX y XX son, en este aspecto fundamental, pequeñas o grandes prisiones (Rodríguez y Triviños 2006). Cárceles que aprisionan los deseos perturbadores, la libertad de los flujos de vida. Máquinas de corte barridas en todos sus rincones por el ojo implacable de un narrador que vigila, siempre auxiliado por la luz, que nada ni nadie escape, que los héroes portadores del deseo transgresor pasen por rituales de expulsión que, más allá de sus diferencias específicas (locura, muerte, soledad, renuncia), obedecen a una misma ley narrativa: la ley del realismo que, según Bersani, es el miedo al deseo. Una cifra, entre otras igualmente estremecedoras de la gran literatura realista española, es la conclusión de La Regenta. El beso repugnante del hombre-sapo irrisiona así la imaginación romántica de la protagonista:

Celedonio, el acólito afeminado, alto y escuálido, con la sotana corta y sucia, venía de capilla en capilla cerrando verjas. Las llaves del manojo sonaban chocando.

Llegó a la capilla del Magistral y cerró con estrépito.

Después de cerrar tuvo aprensión de haber oído algo allí dentro; pegó el rostro a la verja y miró hacia el fondo de la capilla, escudriñando en la oscuridad. Debajo de la lámpara se le figuró ver una sombra mayor que otras veces...

Y entonces redobló la atención y oyó un rumor como un quejido débil, como un suspiro.

Abrió, entró y reconoció a la Regenta, desmayada.

Celedonio sintió un deseo miserable, una perversión de la perversión de su 
lascivia; y por gozar un placer extraño, o por probar si lo gozaba, inclinó el rostro asqueroso sobre el de la Regenta y le besó los labios.

Ana volvió a la vida rasgando las nieblas de un delirio que le causaba náuseas.

Había creído sentir sobre la boca el vientre viscoso y frío de un sapo (Alas, 1997: 790-791).

Existe, no obstante, una diferencia entre el vigilante ideado por Bentham y el de la novela realista. La figura omnicontemplativa del ojo del poder narrativo tiene unas características inconcebibles en el aparato panóptico real: el vigilante está atraído por los deseos perturbadores de los vigilados. Le atraen, pero también les teme. Los reprime, pero está fascinado por ellos. Esta es la norma, dice Bersani, no la excepción. Rojo y negro, Fortunata y Jacinta, Madame Bovary, La fontana de oro, Montaña adentro, La batalla de los Arapiles, La Regenta, Moby Dick, Mariluán, Crimen y castigo y La Cartuja de Palma, por ejemplo, sugieren panópticos por la "presencia universal y constante del gobernador del establecimiento" llamado narrador omnisciente. El dispositivo novelesco opera, sin embargo, escandalosamente al revés, porque en vez de disciplinar los deseos "nocivos" del protagonista los libera. El realismo es indiscernible en este sentido de la represión del libre fluir del deseo. Los ceremoniales finales de exclusión de lo perturbador, con todo, no logran silenciar el secreto de esta fluencia. Tal vez hay dos grandes clases de relatos realistas: al derecho y al revés. La singularidad de los primeros sería el ocultamiento de la fascinación. El des-cubrimiento de la atracción, el signo distintivo de los segundos. Acaso podría establecerse, poniendo en relación los mismos textos señalados, otra clasificación. Aquella que distingue entre novelas cuyos ceremoniales de expulsión sugieren el triunfo del mecanismo disciplinario y novelas que revelan el carácter ilusorio, falaz, de esa victoria. Periquillo Sarniento o la domesticación del pícaro: mentira panóptica. Mariluán o la muerte fecunda del rebelde: verdad novelesca. Las narraciones realistas artísticamente superiores serían, entonces, las que descubren la "regla del mundo" ocultada en la "utopía programa" llamada panóptico: la verdad de la indestructibilidad del deseo. Poder de los hechos, poder de la idea que podría definirse así: de una parte, el deseo perturbador está siempre reprimido; de la otra, es indestructible. Aquello que une al panóptico y a la novela es, paradójicamente, su radical incompatibilidad. El panóptico tiene por objeto la reproducción de lo existente. Trabaja para reprimir lo otro, mira incesantemente para que el portador de lo otro temido "pierda en efecto el poder de hacer mal, y casi el pensamiento de intentarlo" (Bentham, 1979: 37). La literatura realista, que también es crítica en acto de la ideología, testimonia finalmente, más allá 
de sus rituales de expulsión, el fracaso de la finalidad misma de toda política de orden prisionera de la ilusión panóptica: "priva(r) a ciertos individuos de la libertad de que han abusado, con el fin de prevenir nuevos delitos, y contener a los otros con el terror del ejemplo" (Bentham, 1979: 35).

El deseo, dice Bersani en "Le réalisme et la peur du desir", es una amenaza para la forma del relato realista. Subvierte el orden social y también hace estallar el orden novelesco. Este es, sin duda, el origen del despliegue de la violencia novelesca contra el imperio de la fuerza disolvente del deseo: "Le roman du XIX siècle est hanté par la possibilité de ces moments subversifs, et il les réprime avec una brutalité qui est á la fois choquante et logique au plus aut. point. En termes formels, le désir est une sorte de gonflement structural; c'est une maladie de la disjonction se développant dans una partie de la structure qui refuse d' etre par rapport aux autres parties et revendique, en quelque sorte, une scandaleuse affinité avec des éléments étrangers á la structure" (1975: 186-187). Gonflement structurel. Esta es, en síntesis, la paradoja constitutiva de la novela realista: admite a los héroes del deseo sólo para someterlos a ceremoniales de expulsión. Muestra atracción por los deseos perturbadores, pero su forma exige, para su existencia misma, la aniquilación o, por lo menos, la matriz paralizante de las tendencias anárquicas. El héroe es literalmente un intruso en el mundo de la literatura realista. Un extraño, sin duda, pero no porque dicho mundo sea el mundo verdadero, incompatible con la libertad del deseo sino porque dicha incompatibilidad es una elección a priori del escritor realista: elección de un mundo de un "género particular" que él se dedica a servir con gran fidelidad:

Les présupposés techniques de la littérature réaliste -la nécessité de personajes 'pleins' et intelligibles, $d$ ' une vraisemblance historique, de gestes ou d'épisodes révélateurs, d'un cadre temporal clos -excluent déjá de cette littérature toute aventure qui, par su stimulante invraisemblance, ne se laisserait pas situer et interpréter dans une structure générale psychologique ou formelle (...) L' étrange imprecisión de certains héros et de certaines héroïnes de roman n'est pas si étrange que cela: en un sens, le roman réaliste ne prévoit pas de tels personajes. Il a très peu à dire á leur sujet. Il peut seulement démontrer que'ils sont étrangers á la société et au livre dans lequel ils ont été placés, avec une certaine perversité (Bersani, 1975: 187-188).

El término perversidad no sorprende en esta formulación. El escritor realista lo es porque proclama la superioridad de una imaginación que él mismo condena inexorablemente; porque a través de su héroe, que es incitación y advertencia a la vez, cede a la tentación de rechazar la sociedad al mismo tiempo que no 
duda en castigar dicha rebelión. Bersani no descubre la razón de esta atrayente perversidad. Lo hace, en cambio, René Girard. El doble movimiento de atracción y repulsión por el deseo incompatible con el orden social y la forma realista se debe acaso a que el novelista escribe en su novela su propia fascinación por el deseo. No, empero, una fascinación actual sino una fascinación ya superada. Don Quijote o el triunfo de Cervantes sobre la pasión caballeresca. La Regenta y Madame Bovary o la victoria de Alas y Flaubert sobre la pasión romántica. Aita Tettauen o la victoria de Galdós sobre la pasión del heroísmo militar.

Una novela del siglo XX tiene gran importancia dentro de lo que podríamos llamar la historia hispánica, aún no escrita, de las insurrecciones del deseo contra el dispositivo panóptico que funda la ilusión del disciplinamiento de sus flujos en la alucinación del lector por la verosimilitud o mimesis, "ignominia del Arte". Es el Museo de la Novela de la Eterna, intento de demolición de los cimientos mismos del realismo (tendencia estética) y la solemnidad (estilo). Macedonio Fernández, su autor, cifra así la escisión acaso más escandalosa y más conmovedora a la vez entre el deseo y el orden realista, entre la pasión metafísica y la forma realista: "mi novela tiene lo sagrado, la fascinación de ser el Dónde a que descenderá fresca la Amada volviendo de una muerte que no le fue superior, que no necesitó Ella para purificarse y sí sólo para inquietar el amor y por ello descenderá fresca de muerte, no resucitada sino renacida, sonriente como partió y con apenas un solo ayer de su ausencia de años" (Fernández, 1996: 26). Las reverberaciones de este deseo de creación del lugar del descenso de la Amada muerta son infinitas. Anoto sólo un efecto de máximo extrañamiento dentro de la tradición realista: el estallido de lo que hace posible, según Girard, la escritura misma de la novela: el triunfo del escritor, concentrado en la conclusión narrativa, sobre la fascinación del deseo. Todas las conclusiones novelescas, dice el autor de Mentira romántica y verdad novelesca, son conversiones en las cuales el triunfo estético del novelista se confunde con la alegría del héroe que ha renunciado al deseo: "El héroe sucumbe para alcanzar la verdad y confía a su creador el legado de su clarividencia. Hay que reservar el título de héroe de novela al personaje que triunfa sobre el deseo metafísico en un final trágico volviéndose, así, capaz de escribir la novela (...). Es de la ruptura con el mediador de donde surge la inspiración novelesca” (Girard, 1963: 216-217). Conversión que es comienzo, tiempo recobrado, memoria de la liberación del deseo. El origen de Museo de la Novela de la Eterna es, por el contrario, la pasión metafísica intensamente actual del autor, (en)sueño del presente mismo de la enunciación novelesca. Ni perversidad que proclama la superioridad del deseo destinado a su aniquilación, ni prudencia propia del héroe-escritor cuya ausencia actual de deseo le permite resucitar su locura pasada, sino fluir ostentoso, libérrimo, de 
un delirio que nada extingue, que nada ni nadie intenta controlar, someter a los rituales panópticos de la expulsión. La escritura del deseo sin límites en Macedonio Fernández testimonia en este sentido la incompatibilidad entre el fluir irreprimible del deseo, que siempre cuestiona las estructuras establecidas y que es revolucionario porque siempre quiere más conexiones y más agenciamientos (Deleuze y Parnet, 1997: 91), y la forma realista regida por la necesidad de personajes "plenos", congruencia de caracteres, verosimilitud histórica, nitidez de fronteras entre realidad y ficción, cuadro temporal cerrado, cohesión narrativa y rituales de expulsión: "Non seulement la société telle que’elle est représentée dans la littérature réaliste ne parvient pas à fournir les occasions propices á l'accomplissement des passions exceptionnelles, mais la forme meme du roman réaliste est incasable d'acueillir de telles passions. A mesure que le désir perturbe plus fondamentalement l'ordre établi, le roman tend á devenir moins réaliste, plus allégorique" (Bersani, 1975: 187). El mismo novelista legitima el nombre que le conviene a la "primera novela genuina artística": novela fantástica: "novela en que la Imposibilidad, de situaciones y caracteres, que es el criterio para clasificar algo como artístico sin complicación de Historia, ni Fisiología, se ha cuidado tanto, que nadie, ningún conocedor cotidiano de imposibles, ninguno a quienes le sean familiares, podrá desmentir la constante fantasía de nuestro relato alegando que hechos o personajes los tiene vistos enfrente o a la vuelta" (Fernández, 1996: 14): ni mimesis, ni realismo, ni representación, sino creación, experimentación, fantasía. Imperio del deseo: Museo de la Novela de la Eterna o la desintegración de la máquina panóptica. Apoteosis del viaje sin vigilancia hacia la alteridad llamada Muerte. Aventura artística y metafísica por excelencia: búsqueda de la no muerte.

Sorprende que los estudiosos de la novela que así libera el deseo reprimido por el realismo afirmen que las motivaciones de su autor pertenecen a un "terreno extra-artístico". Parecen olvidar con ello que la fuerza subversiva, disolvente, del Museo de la Novela de la Eterna reside precisamente en la disolución de los fronteras entre "reinos heterogéneos", en el traspaso de los límites que separan literatura y filosofía, novela y metafísica, poesía y ciencia, ficción y realidad, vigilia y ensueño, teoría y práctica, arte y religión, razón y fantasía. No hay motivaciones extra-artísticas en Macedonio Fernández. Hay sólo devenires creadores de agenciamientos impensados, bodas contra natura que permiten el fluir sin límites, sin restricciones, de la pasión metafísica. La boda más bella, más disolvente, de la escritura de Fernández es precisamente la que impide llamar "extra-artístico" al "anhelo que (la) anima": el encuentro, imposible en la novela panóptica, de la literatura y la metafísica, de la razón filosófica y el "Ilogismo llamado Humorística”. 
Ricardo Piglia señala con precisión el "delirio filosófico" que deviene matriz de escritura en el Museo de la Novela de la Eterna:

El amor como cliché narrativo. En el Museo la historia de la Eterna, de la mujer perdida desencadena el delirio filosófico. Se construyen complejas construcciones y mundos alternativos. Lo mismo pasa en $E l$ aleph de Borges, que parece una versión microscópica del Museo. El objeto mágico donde se concentra todo el universo sustituye a la mujer que se ha perdido. Curiosamente, varias de las mejores novelas argentinas cuentan lo mismo. En Adán Buenosayres, en Rayuela, en Los siete locos, en el Museo de la Novela de la Eterna, la pérdida de la mujer (se llame Solveig, la Maga, Elsa o la Eterna, o se llame Beatriz Viterbo) es la condición de la experiencia metafísica. El héroe comienza a ver la realidad tal cual es y percibe sus secretos. Todo el universo se concentra en un 'museo' fantástico y filosófico (Piglia, 1996: 519).

El autor de Notas sobre Macedonio en un Diario no precisa empero las diferencias entre los textos por él vinculados. Hay, en efecto, desemejanzas radicales. Museo de la Novela de la Eterna no narra, como El aleph, por ejemplo, el descubrimiento, hallazgo o encuentro del objeto mágico que sustituye a la mujer perdida. Narra, por el contrario, su invención, su creación, su construcción. El protagonista no halla el objeto, lo crea. La novela misma es aquí el Génesis. Génesis de lo nunca sido. Creación que roza lo sagrado. Escribir, ya lo sabemos, es devenir otra cosa que escritor: devenir-indio, devenir-mujer, devenir-ballena, devenir-cucaracha, devenir-rata, devenir-perro, devenir-niño, devenir-viento, devenir- molécula. Los devenires del escritor en Museo de la Novela de la Eterna son múltiples, pero uno de ellos se destaca por su singular fuerza destructiva y creadora a la vez. Es su devenir-hacedor de un hogar para la espera de la bella muerta: salto nunca fabulado en la novela hispánica dominada por el principio panóptico: agenciamiento de la metafísica y la literatura que provoca la fascinación propia de lo sagrado:

El anhelo que me animó en la construcción de mi novela fue crear un hogar, hacerla un hogar para la no-existencia en que necesita hallarse Deunamor, el No-Existente Caballero, para tener un estado de efectividad, ser real en su espera, situándolo en alguna región o morada digna de la sutilitad de su ser y exquisitez de su aspiración para poder ser encontrado en alguna parte, en mi novela mientras espera, y cuando llega de vuelta de la muerte su amada, que él llama la bellamuerta, es decir que embelleció a la muerte con su sonreír, en el morir y que sólo tuvo muerte de Beldad. Morada para la espera de la 
bellamuerte. (Mi) novela tiene lo sagrado, la fascinación de ser el Dónde a que descenderá fresca la Amada volviendo de una muerte que no le fue superior, que no necesitó Ella para purificarse" (Fernández 1996:22).

Escribir, leemos en Conversaciones de Deleuze, no es comunicar sino resistir. La fuerza perturbadora del Museo de la Novela de la Eterna se cifra, entre otras múltiples posibilidades, en esta clave de lectura. Su autor, en efecto, no se propone informar, imitar, comunicar o adoctrinar en la novela que se llama a sí misma "un total ensueño, un ensueño entero". Su pasión, su locura tienen una única finalidad: tejer y destejer, como Penélope, un mismo hilo, una misma línea de fuga de la muerte. El texto mismo en su totalidad, definida como el hogar de la espera del descendimiento de "la Amada volviendo de una muerte que no le fue superior", testimonia el apasionante trazado de líneas de fuga de la negatividad suprema que el novelista sigue forzosamente porque la escritura lo compromete con ellas en una especie de delirio con algo de demoníaco o demótico en el sentido de Deleuze:

La diferencia entre los demonios y los dioses estriba en que éstos tienen atributos, propiedades y funciones fijas, territorios y códigos: tienen que ver con los surcos, los lindes y los catastros. Lo propio de los demonios, por el contrario, es saltar los intervalos, y de un intervalo a otro. '¿Cuál es el demonio que más ha saltado?', pregunta Edipo. En una línea de fuga siempre hay traición. Nada de trampear como un hombre de orden que prepara su porvenir, sino al contrario, traicionar, traicionar a la manera de un hombre simple que no tiene ni pasado ni futuro. Traicionar las fuerzas estables que quieren retenernos, los poderes establecidos de la tierra” (Deleuze y Parnet, 1997: 50).

Invención de una línea de fuga y el poder de la traición. Este es acaso el mayor secreto creador del escritor que deviene fugitivo de la muerte en su escritura. Secreto cuya comprensión sólo requiere liberarse del único error: "el gran error, el único error, sería creer que una línea de fuga consiste en huir de la vida, evadirse en lo imaginario o en el arte. Al contrario, huir es producir lo real, crear vida, encontrar un arma" (Deleuze y Parnet, 1997: 58). Eso que es precisamente la intensa línea de fuga llamada Museo de la Novela de la Eterna: producción de lo real, no su mimesis: creación de vida, no su evasión: encuentro de un arma para resistir, no retiro a lo imaginario.

Entrega a la línea de escritura que permite arrostrar la línea del Afuera, la línea mortal demasiado violenta y demasiado rápida que nos introduce en una atmósfera irrespirable. Deleuze, lector de Foucault, no leyó a Macedonio 
Fernández. Habría encontrado entonces uno de los testimonios literarios más fascinantes del enfrentamiento de la línea del Afuera. ¿Qué otra cosa es si no Museo de la Novela de la Eterna, que su autor comienza a escribir en 1904 y que no concluye ni siquiera en 1952, año de su muerte? ¿Qué otra cosa si no la relación con la línea que, "como la droga a la que renunció Michaux, destruye todo pensamiento (y no) es más que delirio o locura, como la 'monomanía' del capitán Achab"? (Deleuze, 1995: 181). La "misma cuestión" de "vida o muerte", pues, conforma la filosofía-poesía de Roussel a Michaux, pero también la filosofíanovela de Fernández a Bolaño: ¿hasta dónde franquear la línea del Afuera y, al mismo tiempo, hacerla susceptible de ser vivida?, ¿hasta dónde es posible desplegarla sin caer en un vacío irrespirable, en la muerte?, ¿cómo plegarla sin perder el contacto con ella, constituyendo "un adentro compresente" al afuera, aplicable al afuera?, ¿cómo hacer de ella, en la medida de lo posible, y durante todo el tiempo que fuera posible, un arte de vivir? (Deleuze, 1995: 180-181).

Las provocadoras figuras de Deunamor, la Bellamuerta y el Autor, tríada protagonista de la aventura creadora de un hogar para la muerta bella, que es la novela misma llamada Museo de la Novela de la Eterna, no son, con toda su espesura significativa, las únicas huellas estéticas de la fuga que permite a Macedonio Fernández plegar y desplegar la línea del Afuera para llegar a vivir "en ella, con ella". Hay otras zonas del texto también fundamentales para el estudio de la "cuestión de vida o muerte" en la escritura de Fernández. Me refiero específicamente a la ausencia de escenas de muerte en el Museo de la Novela de la Eterna. Ausencia que escandaliza, sin duda, dentro de la novela realista, inimaginable sin las muertes literales o simbólicas propias de los ceremoniales de expulsión de la máquina panóptica, pero no en la novela metafísica o metafisica fantaseada que resiste la línea que "no es más que delirio o locura" agenciando la literatura con la filosofía, la "humorística" con el ensueño. Museo de la Novela de la Eterna es en este aspecto radicalmente "antirrealista". Las ocurrencias del significante muerte son en ella múltiples, pero nadie muere (ni tampoco vive). Este es el grado cero del hápax en el comienzo que evita ser comienzo, en el desarrollo del "cuento" y en el final que evita ser final en el Museo de la Novela de la Eterna. No sólo eso. Esta escritura de ausencia no se limita a negarle espacio textual a las escenas de muerte. También proclama de modo explícito, deliberadamente marcado, dicha exclusión en numerosos momentos de su teoría y de su práctica novelescas. Anoto los ejemplos sólo más provocativos de esta negación de la negación:

Nadie muere en ella -aunque ella es mortal- pues ha comprendido que, gente de fantasía, los personajes, perece toda junta al concluir el relato. Tarea 
innecesaria que se toman los autores, con peligros de olvidos y de repetirle la muerte a alguno, de dar aquí y allá expiración de cada protagonista, como anda el sacristán apagando luces hacia el fin de la misa, por no dejar al pez vivo sin agua, al 'personaje' sin novela.

Y más, que tengo seguridad que nadie vivo se ha entrado a la narrativa, pues personajes con fisiología, además de muy estorbados de cansancios e indisposiciones, - por lo que no se ve a protagonistas enfermarse como parte de su trabajo y continuar figuración activa de enfermos y moribundos-, son de estética realista y nuestra estética es la inventiva (Fernández, 1996: 13).

El Cuaderno 1925, de Inéditos II, de la Edición Allca XX/ Fondo de Cultura Económica, por la que estoy citando, reitera en clave humorística el mismo signo distintivo de la narrativa de Macedonio Fernández: "No figurarán muertos en mis novelas porque mis personajes son gente de vergüenza que se ruborizarían de morir a haberlo hecho" (Fernández, 1996: 319). El texto 59 del Cuaderno 1927-28, incluido en la sección ya señalada, reitera la misma gran exclusión de aquello que, paradójicamente, se nombra una y otra vez: Es la historia del tiro retirado de la obra teatral porque el personaje no cree en la muerte:

Señores, dentro de poco va sonar un tiro en el escenario; discúlpennos, es un tiro de pura pólvora, absolutamente no para la muerte de uno u otro personaje.- Este anuncio lo repite de tiempo en tiempo, y al fin dice: El tiro ha sido retirado de la obra porque se ha tornado inútil en razón de que el personaje, que debía sentenciar también al público, al resistir el plano mortal ha declarado que no cree en la muerte, y es opuesto, por ello, a escenas inútiles, y no quiere engañar al público como si él fuera un personaje irreal de novela, añadiendo que a veces se olvidan de poner el cartucho sin bala en los revólveres de (+), lo que sería una informalidad que no le gusta. No hemos tenido pues tiro, pero conste que para un tiro no disparado bastante lo he anunciado (Fernández, 1996: 324).

Escenas inútiles. El estallido de la materia narrativa misma de la literatura realista, fundada en la verosimilitud, en la ilusión de la mimesis, es, pues, total: el autor, pero también los personajes, pero también la novela no quieren "que haya 'donde se llama y no contestan': la Muerte” (Fernández, 1996: 305). Existe, empero, una forma de muerte que no se niega en Museo de la Novela de la Eterna. Es la "muerte académica" de los personajes. Ocurre cuando la novela se termina. Aun aquí parece triunfar la pasión negadora de la muerte. No otro 
es el sentido del diferimiento del final novelesco. El relato parece finalizar con "La Noticia última", pero se reinicia con el "Epílogo", después con el "Intento de sedación de una herida que se tiene en cuenta", después con "La novela en estados" y después con "Al que quiera escribir esta novela". Libro, pues, abierto a la corrección de "todo escritor futuro de buen gusto", sobre todo porque "está muy lejos de cumplir la fórmula de la belarte de personajes por la palabra. Queda también esto, pues, como 'empresa abierta'”(1996: 253-254).

El Capítulo XVIII y la Noticia Ultima son, con todo, particularmente sugestivos dentro del tropismo de fuga de las escenas de muerte en el espacio novelesco. Antes de la edición de la novela, momento del cumplimiento de "la dispersión de las espaldas, la despedida sin mirarse, la muerte académica”, el autor narra al lector lo que sucede cuando el Presidente avisa a sus invitados que dejará "La Novela": los personajes presufren la despedida mortal mediante una despedida que es eterna de tal modo que ninguno de ellos conocerá por otros "la despedida por muerte". Simple es el único que insinúa rebelarse contra la decisión de abandonar "La Novela", pero Deunamor, el hombre a quien la muerte promete más, se aleja diciendo con expresión muy grave que lo dejen pasar. La Muerte, dice de él la voz del narrador, era su Verdad.

Esta superabundancia de momentos de inclusión-exclusión del significante muerte se expande aún mucho más allá del relato de primer grado, o incluyente, denominado Museo de la Novela de la Eterna. Domina por igual en los relatos de segundo grado, o incluidos, en la novela del autor. Me refiero especialmente a la "Novela en La Novela" que piensa escribir el Presidente y que nunca escribirá, según él, y al cuento "muy trágico" contado por Quizagenio a Dulce-Persona: El asesino anual.

La "novela sin mundo" imaginada por el Presidente se funda en dos principios también constitutivos de la novela del autor: el descrédito de la novela realista y la inclusión-exclusión de la muerte. La subversión de las fronteras de lo decible es, en efecto, radical: el flujo sin control del deseo impide sin cesar el dispositivo panóptico de vigilancia y represión: forma realista, narrador omnisciente, verosimilitud temporal y espacial, personajes plenos, rituales de expulsión:

Los personajes de esta novela, pues, carecen de cuerpo físico, de órganos de sentido, de cosmos (...) El efecto conciencial que busca este novelismo es delinear en la intelección del lector el mero ser conciencial sin mundo, como una posibilidad inteligible. Desacreditar todo el librerío de novelas que ya no es tiempo, narrativas de sucesos de conventillo, de hombre actuante sobre el mundo y actuando por el mundo; la conciencia sin causa, cuya operativi- 
dad se presenta (...) La novela debe desarrollarse en un clima sin disturbios, reyertas, celos, aunque existan las tristezas de la vida, como agrupamiento intercausal directo e inespecial (las otras conciencias son el mundo, exterior de cada conciencia). Vivientes que no se dibujan ni describen, casa que no hay; juego con la muerte que ocurre y nunca mata; Donde Todo Vuelve De La Muerte. Los personajes mil veces vueltos de la muerte, de automuerte por mero deseo, sin veneno ni puñal; que tienen a la muerte por un dormir sin horario, no nocturno. (La muerte no es la policialidad que conocemos, sino una mesa eternamente concurrida y de la que se levanta uno y dice: yo me voy a dormir; eso es la muerte.) (Fernández, 1996: 225).

El diseño de las prefiguras de los personajes de la automuerte por mero deseo está regido por el mismo delirio de negar la muerte a la vez que se la afirma. Los siguientes itinerarios narrativos programados para los personajes testimonian, entre otros, la profunda relación entre novela y muerte en las Notas del Presidente: Postumia: "la que desea ser amada muerta, sólo muerta ser amada". Suicidia: "muere a cada instante 'por su propia mano'". No-olvidable: "no consiente ni aún en la muerte conciencial saberse olvidada". Volupta: "aspira a un beso de un año y morir". Bellamuerta: "la por haber más amor ida, por exaltar el amor". Indiferente: "le interesa exactamente igual la conciencia o la muerte eternas. Hace temblar a todos con esta santidad de indiferencia". Pretendiente a la Vida: "quiere volver al mundo corporal, en el que debió ser muy feliz, por rarísima excepción". Mnemonia: "sólo tiene memoria, carece de ser actual y vida. Pero posee la memoria perfecta: no hay hecho, por instantáneo, por insignificante, que no lo tenga en presente, que no pueda revivirlo". Inminao Inminia: "sólo os ama muerto. No quiere ser amada. Se alarma o repugna de toda caricia o interés por ella. Dice, a todos, en una conversación: 'He hallado a Minuerto. Cuán feliz soy. Pero a veces no lo soy. Pobrecito, que sería si yo muriera.' (Buscaba al hombre cuya expresión delatara que iba a tener la suerte de morir pronto, para ser feliz cuanto antes; no deseaba la muerte de nadie, pero buscaba la muerte que la expresara.)". Eterna: "no conoce muerte; no tiene su conciencia un instante de suspensión. Máxima intensidad de la conciencia". Deunamor: "espera a Bellamuerta. Debe obtener la resurrección conciencial de Ella y probarle definitivamente que no hay dicha superior a la plenitud de conciencia en pasión actual, es decir eterna". No-torna: "sin eternidad personal; no vuelve. Todos saben que no tiene más que una vida y una muerte, mereciendo el cuidado, la obsesión de los quienes saben que un buen día podrá escapárseles. Sólo muere por causa; sin una causa no muere. Se desvelan todos para que esa causa no llegue. Y como no saben cuál es esa causa única, la llenan de exquisite- 
ces de amor y previsión. ¿Pero no será una dicha lo que la aniquile” (Fernández, 1996: 226-228).

El "cuento" de Quizagenio, por su parte, es algo más que una irrisión irónica y burlesca dirigida, según los editores críticos de la novela, contra el "género policial, al que Macedonio subestimaba por su énfasis en el acontecimiento, en el suspense y en los finales develadores del enigma" (Fernández, 1996: 239, Nota d). Algo más también que una metáfora del narrador como supremo hacedor y seductor irresistible que asesina perversamente a sus víctimas cuando se encuentran en el colmo de la felicidad. El personaje que así posee el poder de dar felicidad y quitar la vida no es, empero, un sádico cualquiera. Ejecuta sólo el deseo de un suicida que pide su muerte en el colmo de la felicidad, en la exaltación de la dicha: "Lo que le impulsa es el placer de ver. Quizagenio revela a Dulce-Persona el secreto nunca sabido por sus gratas víctimas: el verdadero problema del asesino anual es que tiene horror a la muerte y confía en que, gracias a ver morir dulcemente, rehabilitará su valor y podrá allanarse a la muerte: "lo que le impulsa es el placer de ver morir; está aprendiendo y adquiriendo la sonrisa del morir, para cuando él muera" (Fernández, 1996: 240).

El secreto del personaje que dice "yo no puedo vivir feliz si no realizo un asesinato cada año" tiene gran importancia para el estudio de las relaciones entre escritura y muerte en Museo de la Novela de la Eterna. Testimonia otros sentidos de la novela del estallido total de los fundamentos mismos de la novela realista dominada por los ceremoniales de expulsión del deseo. Ese deseo que fluye incontenible para experimentar el conjuro del horror de la muerte, para adquirir la sonrisa del morir cifrada en la locura del asesino dual. El Museo de la Novela de la Eterna es sin duda el hogar de la esperanza del retorno de la amada muerta de Deunamor, o la morada de la Eterna donde nadie muere, pero también el lugar en el que el propio autor imagina, crea, inventa su propia muerte: la muerte contenta, sonriente. Muerte como la fabulada por Rilke: la muerte profundamente formada por un buen trabajo. Muerte propia que tanto nos necesita, porque la vivimos y de la que nunca estamos tan cerca de aquí. Indigencia que debemos colmar, completa Blanchot, y que no es temible más que por el desamparo que la separa de nosotros: sostener, dar forma a nuestra nada. Esa es la tarea: "debemos ser los diseñadores y los poetas de nuestra muerte" (Blanchot, 2000: 117). Es notable, en este sentido, la fuerza sugestiva de la "muerte feliz" de "El asesino anual". Evoca, entre otras reverberaciones, la "muerte contenta" de Kafka. El escritor que Fernández admiró intensamente (“igenio, genio!”) dice en su Diario:

cuando volvía a casa, declaré a Max que, si los dolores no son excesivos, me 
sentiré muy tranquilo en mi lecho de muerte. Me olvidé agregar, y luego lo omití adrede, que lo mejor que he escrito hasta ahora se basa en esta capacidad de poder morir contento. Todos estos buenos pasajes, realmente convincentes, tratan siempre de alguien que se muere y a quien le cuesta mucho morirse, alguien que lo considera una injusticia y por lo menos una crueldad; y eso es lo que conmueve al lector, por lo menos así lo creo. Para mí , en cambio, que creo ser capaz de aceptar tranquilamente la muerte, semejantes escenas son secretamente un juego, es más, me regocija morir la muerte del que se muere; por lo tanto, utilizo astutamente la atención del lector concentrada en la muerte, la comprendo mucho más claramente que él, ya que supongo que él se quejará en su lecho y por eso mismo mi queja es la más perfecta posible; además, no se interrumpe repentinamente como las quejas reales, sólo se apaga hermosa y puramente (Kafka, en Blanchot, 2000: 82).

¿La capacidad de escribir se vincula entonces con la capacidad de morir bien? ¿Los juegos de Kafka y Fernández con la muerte de sus personajes son una forma de aproximarse a sus propias muertes, disimuladas en el hecho de escribir? ¿Se escribe para no morir, para alejar a la muerte, pero también para morir, para aproximarse a Ella? Kafka $y$ Fernández. Unamuno $y$ Jiménez. Neruda $y$ Mistral...: lo que importa, en todo caso, es que todos estos creadores, más allá de sus diferencias, están comprometidos en una relación profunda con la muerte. Todos por igual, diría Blanchot, quieren que la muerte sea posible, unos para alcanzarla, otros para mantenerla a distancia. Las diferencias son mínimas, pues se inscriben en un mismo horizonte: establecer con la muerte una relación de libertad. Línea de fuga, enrostramiento del Afuera, relación de soberanía. La cuestión de vida o muerte otra vez: ¡cómo salvarse, en el enfrentamiento con la línea demasiado violenta y demasiado rápida?, ¿cómo resistir la línea que "no cesa de desplegarse a una velocidad desenfrenada mientras nosotros intentamos plegarla para constituir esos 'seres lentos que somos' y para llegar 'al ojo del huracán', como decía Michaux: ambas cosas a la vez” (Deleuze, 1995: 178-179).

Pliegue de la línea del Afuera para lograr vivir en ella, con ella. Me maravilla en este sentido la definición de la novela "antirrealista" dada por el propio Fernández: doblez del mundo. Ni espejo, ni imitación, ni mimesis, ni representación, sino doblez del mundo, pliegue de la línea mortal sin el cual es imposible respirar, pensar, escribir. Las pruebas textuales de la profunda relación de la novela "sublime y difícil" con la muerte son múltiples. La mayor de ellas es, sin embargo, la materialidad misma del texto, el mismo objeto artístico llamado Museo de la Novela de la Eterna. Macedonio Fernández, como Franz Kafka, revela así la verdad del arte. Sólo se puede escribir, dice uno y otro, cuando se es 
dueño de sí frente a la muerte, cuando se establecen con ella relaciones de soberanía: "si frente a la muerte se pierde la compostura, si ella es algo incontenible, entonces corta la palabra, no se puede escribir; el escritor ya no escribe, grita, un grito torpe, confuso, que nadie oye o que no emociona a nadie" (Blanchot, 2000: 82-83). ¿El arte es dominio del momento supremo, supremo dominio de la posibilidad extrema? Museo de la Novela de la Eterna permite vislumbrar una respuesta. Nos dice, por lo menos, que la metamorfosis de la suprema negatividad que petrifica, como al niño paralizado de terror en Diario de muerte de Enrique Lihn, en suprema positividad que permite escribir, es una forma de respirar, de residir en y con la línea que no es más que delirio y locura. Esa positividad que hace posible, por ejemplo, los juegos de la Novela de la Eterna (primer grado), donde ni el autor, ni los personajes, ni la novela quieren que la muerte ocurra, o los juegos de la "novela en La Novela", donde la muerte ocurre, pero nunca mata, porque "Todo Vuelve de la Muerte".

Novela, en síntesis, del libre fluir de los juegos con la muerte que paralizan todo saber y todo poder regido por el mito panóptico. Exploración del misterio mortal incompatible con la forma realista. Clausura escandalosa del vigilante represor de los deseos perturbadores. Metamorfosis de la negatividad suprema de la línea mortal en suprema positividad. Creación de un hogar para el descendimiento de la muerta bella. Línea de fuga que no es evasión en lo imaginario sino creación de vida en la que la muerte es lo que hay que hacer: "una tarea, aquello de lo que nos apoderamos activamente, lo que se hace fuente de nuestra actividad y nuestro dominio". Ensueño de "sonreída muerte"...

Todas estas formas de cifrar los sentidos olvidados de Museo de la Novela de la Eterna no señalan una conclusión. Indican, por el contrario, un comienzo. Acaso porque sólo ahora, en este final ilusorio, puedo proponer un nombre para la novela que arrastra sin cesar a nuevos vértigos del pensamiento. Novela metafisica. Metafisica fantaseada. Primera novela buena. Novela fantástica. Novela sublime y difícil... Son nombres dados por el propio autor. Hay uno, empero, que también le conviene, entre otros dados por sus estudiosos. Es el nombre novela utópica o utopía novelesca. ¿Por qué? Porque en ella proliferarán los lugares de la metamorfosis de lo imposible en lugares de lo posible. Utopía: lo que no tiene lugar, todavía, leemos en Respiración artificial de Ricardo Piglia. Utopía: lo que tiene lugar en el espacio novelesco emancipado de las restricciones, censuras y expulsiones del orden panóptico predominante en la forma realista, dice mucho la novela de Macedonio Fernández que es infinita como el libro de arena de Borges.

Cuatro son los lugares del triunfo de la imaginación utópica (liberación del deseo) sobre la imaginación realista (represión del deseo) en Museo de la 
Novela de la Eterna: la novela del Autor, La Novela (Estancia), la novela en la novela del Presidente y Buenos Aires. Cinco los bienes supremos poseídos por los personajes: la felicidad, la amistad, la no muerte, el misterio y la belleza. El resto, en el sentido de Bloch, envía a las palabras sin las cuales no es posible la imaginación utópica: (en)sueño, espera y esperanza. Las tres palabras claves, precisamente, del comienzo y del final una y otra vez diferidos de Museo de la Novela de la Eterna: el sueño del imaginador de la no muerte que dice "somos un soñar sin límite y sólo soñar. No podemos, pues, tener idea de lo que un nosoñar" (Fernández, 1996: 24). La espera de Deunamor en la novela del autor: "El anhelo que me animó en la construcción de mi novela fue (hacer un hogar) para la no-existencia en que necesita hallarse Deunamor (...) para poder ser encontrado en alguna parte, en mi novela, mientras espera, y cuando llega de vuelta de la muerte su amada, que él llama la bellamuerta" (Fernández, 1996: 22). La esperanza de los moradores de La Novela: "queda la esperanza con los que quedan en La Novela" (Fernández, 1996: 246).

Museo de la Novela de la Eterna: murmullo de la esperanza contra la negatividad radical que Bloch llama el más duro rechazo de la utopía y, por ello, su inolvidada provocadora: estremecimiento de un apóstrofe impensable: "Muerte, ¿dónde está tu victoria, dónde está tu aguijón?”: fuerza del deseo emancipado de las restricciones "realistas", panópticas, de lo decible sobre el misterio, la muerte y la belleza.

\section{REFERENCIAS}

Alas, Leopoldo. 1997. La regenta. Madrid: Espasa-Calpe.

Bentham, Jeremías. 1979. El panóptico. Madrid: Las Ediciones de la Piqueta.

Bersani, Leo. 1975. "Le réalisme et la peur du désir", en Poétique 22, pp. $177-$ 195.

Blanchot, Maurice. 2000. El espacio literario. Barcelona: Paidós Básica. Bloch, Ernst. 2004. El principio esperanza, II. Madrid: Editorial Trotta. Tomo II. Deleuze, Gilles. Conversaciones. 1995. Valencia: Pretextos.

Deleuze, Gilles y Claire Parnet. 1997. Diálogos. Valencia: Pretextos.

Fernández, Macedonio. 1996. Museo de la Novela de la Eterna. Edición crítica. Ana María Camblong-Adolfo de Obieta (Coordinadores). Madrid: Allca XX / Fondo de Cultura Económica, Colección Archivos.

Fernández Moreno, César. 1996. "El existidor”. En Macedonio Fernández, Museo de la Novela de la Eterna, Edición crítica, Madrid: Allca XX / Fondo de Cultura Económica, pp. 550-574. 
Girard, René. 1963. Mentira romántica y verdad novelesca. Caracas: Universidad Central de Venezuela.

Lihn, Enrique. 1999. Diario de muerte. Santiago: Universitaria.

Piglia. Ricardo. 1992. Respiración artificial. Buenos Aires: Sudamericana.

Piglia, Ricardo. 1996. Notas sobre Macedonio en un diario. En Macedonio Fernández, Museo de la Novela de la Eterna: Madrid: Allca XX / Fondo de Cultura Económica, pp. 516-519.

Rodríguez, Mario y Gilberto Triviños (eds.). 2006. Utopía y mentira de la novela panóptica. Concepción: Editorial Universidad de Concepción, Serie Monografías. 